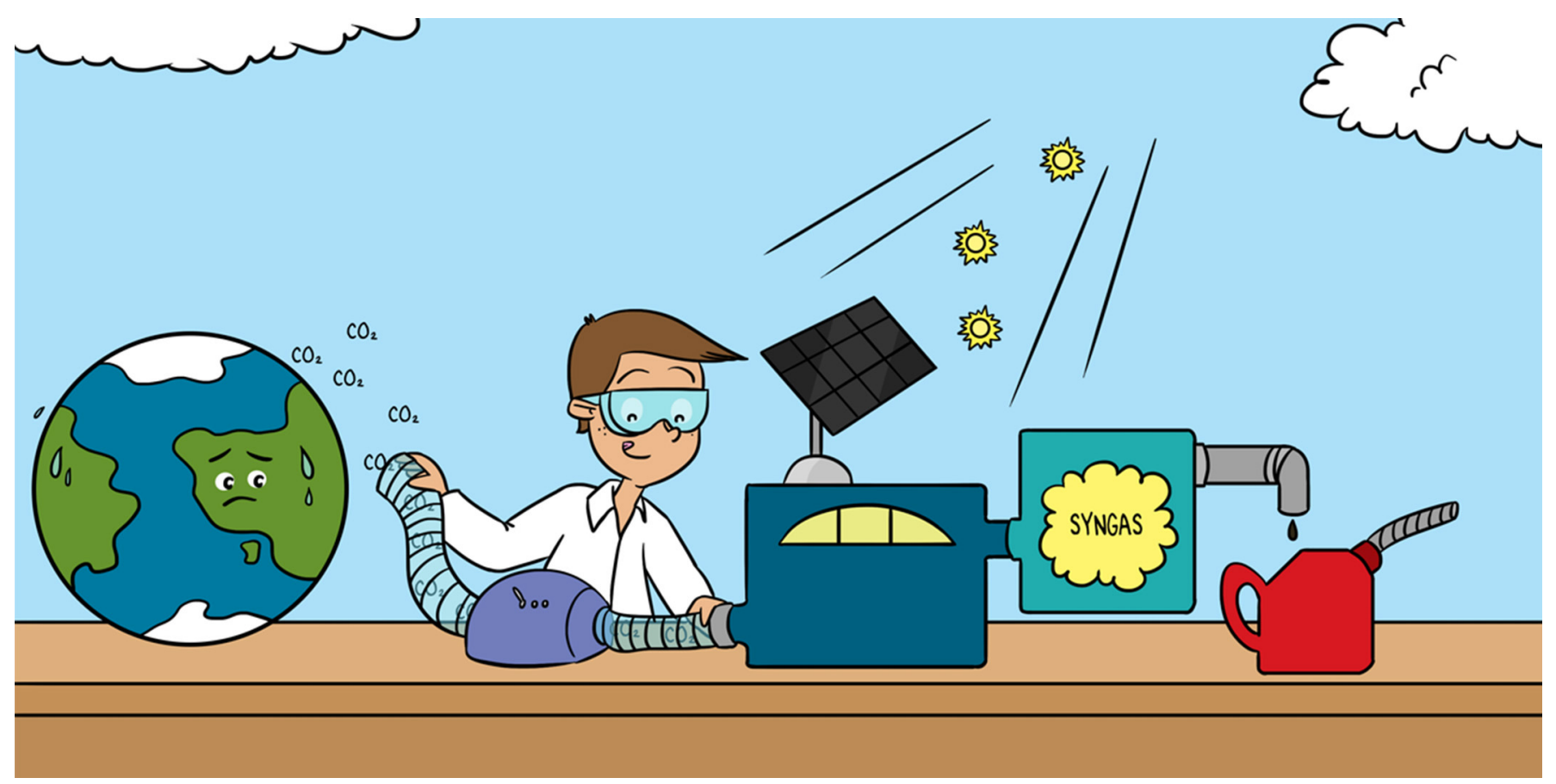

\title{
HOW GREENHOUSE GASES CAN BE USED TO STORE ENERGY
}

Thomas Ruh ${ }^{1 *}$, Verena Pramhaas ${ }^{1}$, Patrizia Bartl ${ }^{2}$ and Christoph Rameshan ${ }^{1 *}$

${ }^{1}$ Institute of Materials Chemistry, TU Wien, Vienna, Austria

${ }^{2}$ Institut für Elementar- und Primärpädagogik, Pedagogical University Tyrol, Innsbruck, Austria

YOUNG REVIEWERS:

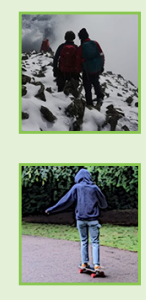

ANDREA

AGE: 15

ELINOR

AGE: 15

ERICA

AGE: 13

GEORGE

AGE: 10

IOLO

AGE: 13
Rising levels of carbon dioxide in Earth's atmosphere are a problem, because they lead to global warming and changes in climate that are serious threats to the environment we live in. So, getting rid of some of the carbon dioxide would be very important to combat the dangerous effects of global warming. One way to reduce the amount of carbon dioxide in the atmosphere is to turn it into chemicals like methanol. This transformation not only reduces carbon dioxide levels in the atmosphere, but also offers a way to store renewable forms of energy like wind or solar energy.

\section{CARBON DIOXIDE AND CLIMATE CHANGE}

Carbon dioxide (a molecule made up from one carbon and two oxygen atoms $-\mathrm{CO}_{2}$ in chemists' notation) is a greenhouse gas, which means it contributes to the so-called greenhouse effect. Carbon dioxide and other greenhouse gases in the air trap some of the heat Earth would lose into space, similar to the way heat is trapped inside a greenhouse, 


\section{GREENHOUSE GAS}

A gas in the atmosphere that traps heat, causing higher temperatures. This effect of greenhouse gases is called the greenhouse effect.

HUMAN-MADE CLIMATE CHANGE

The change in the Earth's climate caused by human activities, such as the large-scale usage of fossil fuels.

\section{ENERGY}

CONVERSION

The process of turning one form of energy (such as wind energy) into another one (such as electrical energy); also called energy transformation. or in a pot with a lid. This trapping of heat is necessary for life as we know it on Earth-without it, the average temperature would be about $-18^{\circ} \mathrm{C}\left(0^{\circ} \mathrm{F}\right)[1]$.

However, $\mathrm{CO}_{2}$ is also the main contributor to human-made climate change and global warming. By burning fossil fuels like oil or natural gas, which were formed over millions of years, we increase the amount of $\mathrm{CO}_{2}$ in the atmosphere. Increased atmospheric $\mathrm{CO}_{2}$ leads to more heat being trapped and to increasing temperatures. As a result, the average global temperature has risen almost a whole degree since humans started using fossil fuels on a large scale for power plants, transportation (cars, planes, etc.), heating, and so on. That might not sound like a big temperature rise, but this slight increase has drastic consequences on the sensitive balance of our environment. For instance, rising sea levels due to melting polar ice might affect coastal cities, or higher ocean water temperatures may threaten coral reefs [2].

Reducing the amount of carbon dioxide in the atmosphere is a very important step to combat global warming. One possible way to do this would be to remove $\mathrm{CO}_{2}$ by turning it into useful chemicals that we can safely store and later use as fuels. There is a slight shortcoming of this method, though: while production of these easy-to-store chemicals reduces $\mathrm{CO}_{2}$, burning them later as fuel will re-release the carbon dioxide into the atmosphere. However, there is no "new" $\mathrm{CO}_{2}$ released into the atmosphere. The carbon dioxide is therefore kept in balance as the fuel is recycled, which is still much better than using fossil fuels and adding new $\mathrm{CO}_{2}$ to the atmosphere.

\section{WHY ARE WE TALKING ABOUT STORING ENERGY?}

Every process you can think of needs energy to take place-for example, plants growing, cars being driven, and even you reading this article. However, this energy is not gone after the process finishes! A very important principle of physics states that energy can be neither created nor destroyed, it is only possible to convert (or transform) energy from one form to another. So, another way of thinking about the processes we mentioned would be to see them as energy conversions. For example, a plant uses energy from the sun to grow, and energy is then stored in the newly grown parts of the plant. In a car, gasoline is burned so that the energy from the fuel can be changed into energy of movement (called kinetic energy) and heat. When you move your eyes to read this article, your body turns the energy provided by the food you eat into movement, and your brain also uses energy to process and remember what you read. All processes that happen-both in nature and using machines-are basically the conversion of one form of energy into another form. 
Figure 1

The potential for harnessing solar or wind energy varies for different regions in the world. On this map, you can see how the average wind speed (blue areas) and the solar potential (red areas) are distributed. You might notice that, surprisingly, the potential for solar energy along the equator is only medium. This is due to clouds that occur in this region of the world (those clouds are also the reason for the large rain forests along the equator). Many areas with very high solar potential are actually deserts $^{1}$

1 The data for this figure was taken from http:// globalsolaratlas.info and http:// globalwindatlas.info.

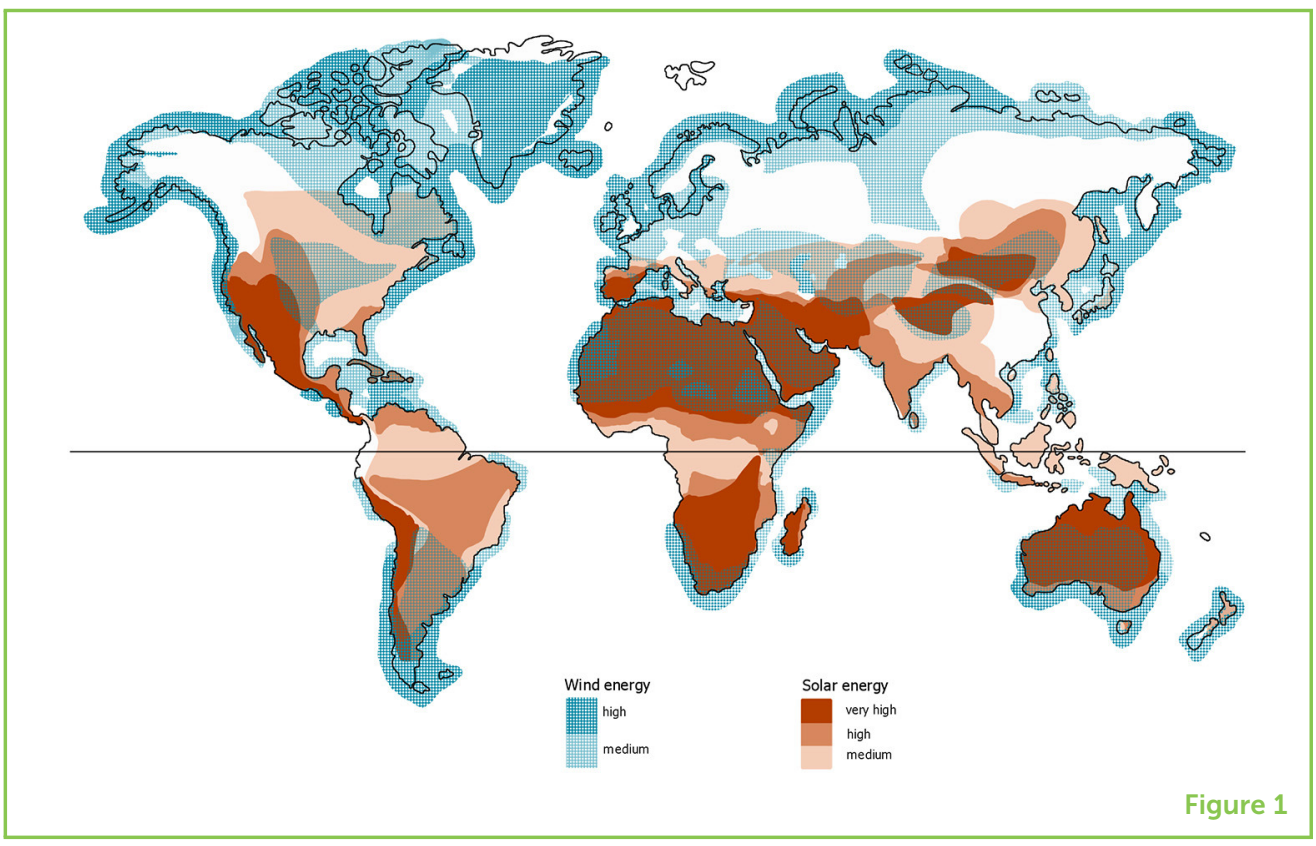

The energy in any process must come from somewhere. Sources of energy include the sun (called solar energy), wind, or water, but also include oil or coal, which are the fossil fuels we still burn on a large scale. Most often, energy from these sources is converted into electricity first, using power plants to convert coal or water, solar cells for sunlight, and wind turbines for wind. The electricity then powers devices like computers and phones, machines in factories, electrically powered cars, and so on. We can also store energy for later use-that is where fuels (sometimes also called energy carriers, because they literally carry energy in them) come in.

Fuels, in any shape or form, are useful for two main reasons-transport and storage. Figure 1 shows that the potential to harness energy from wind and the sun (meaning to make the energy usable) strongly varies for different regions. For instance, in Africa, the potential to harness solar energy is on average greater than in Europe or in North America. The reverse is true for wind energy - the average wind speed is higher in Europe than in Africa, especially near the coasts. And the higher the wind speed, the more electricity can be generated using wind turbines. A consequence of this unequal distribution of energy sources is that we need ways to transport energy to where it is required. With fuels, we can do exactly that: transport energy to where we need it.

Moreover, energy available from the sun and wind does not only depend on where you are, but also on the time-for example, at night we cannot get energy from the sun. Wind speed changes over time as well. During a storm with high wind speeds, for instance, a lot of electricity could be generated-even more than can be used-so sometimes wind turbines must be shut off to prevent damage. If we had a way to store this excess energy, we would not have to shut 
Figure 2

The specific energy contained in different fuels varies. Specific energy is the amount of energy set free when we burn a kilogram of any fuel. The unit of specific energy is joule (J) per kilogram (kg) - the capital M is an abbreviation for "mega," which means that the number shown here are actually millions. The graph shows a comparison of the specific energies in various fuels. A kilogram of methanol contains slightly more energy than a kilogram of wood.

\section{METHANOL}

A chemical that consists of one carbon, one oxygen, and four hydrogen atoms. It belongs to a group of chemicals called alcohols, and can be used to store energy or to produce goods of our daily lives.

\section{SPECIFIC ENERGY}

The amount of energy contained in a kilogram of any fuel. This energy is set free if the fuel is burned.

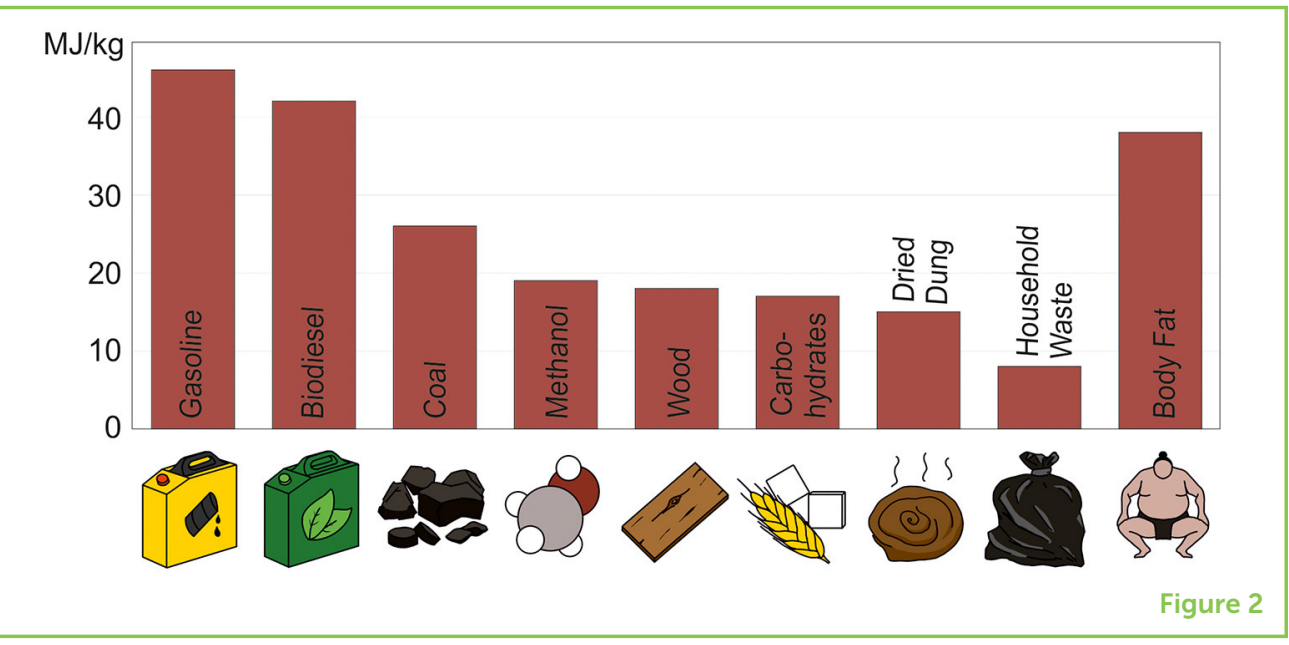

off wind turbines or worry about solar energy when the sun is not shining. Therefore, methods to convert energy into fuels for later use are very interesting.

\section{METHANOL AND ITS MANY USES}

Methanol is a liquid belonging to a family of chemicals that are called alcohols, which simply means it is made up from carbon, hydrogen, and oxygen atoms that are connected in a specific way. The most famous alcohol is ethanol, which is the alcohol contained in alcoholic drinks like beer or wine. Ethanol is so well known that many people say "alcohol" when in fact they mean ethanol, or any drink that contains ethanol. So, you must keep in mind that a chemist means something quite different from an adult at a party when talking about alcohols.

Methanol is the simplest possible alcohol, because it contains only one carbon, one oxygen, and four hydrogen atoms. However, it is still an important chemical. It is used as a raw material to produce a large number of goods we use in our daily lives, like plastics, paints, drugs, fertilizers, and many more [3]. Additionally, methanol can be used to store energy. There are industrial processes that turn methanol into gasoline (similar to the fossil fuel) or into biodiesel, which can then be stored. Methanol itself can be stored as fuel as well. The amount of energy contained in a kilogram of methanol is similar to the amount in a kilogram of wood, as you can see in Figure 2. The figure shows a comparison of the specific energies for different fuels, which means the amount of energy per kilogram material. The higher this value, the more energy the material can store for later use. 
Figure 3

A two-step process for turning carbon dioxide $\left(\mathrm{CO}_{2}\right)$ into renewable fuel. First we take $\mathrm{CO}_{2}$ and water $\left(\mathrm{H}_{2} \mathrm{O}\right)$, put in energy, such as wind or solar energy, and transform the ingredients into syngas, which is a mixture of carbon monoxide (CO) and hydrogen $\left(\mathrm{H}_{2}\right)$, using a solid catalyst. Then the syngas is used in a second step to produce renewable fuel like methanol. In this way, we can store the energy we put into the reaction for later use.

\section{CHEMICAL}

\section{REACTION}

A process in which two (or more) chemicals come together to form new chemicals. For instance, carbon dioxide can react with hydrogen to give methanol and water.

\section{CHEMICAL ENERGY CONVERSION}

The process of turning energy into fuels using chemical reactions. The fuels can then be stored for later used.

\section{CATALYST}

A substance that makes chemical reactions possible that otherwise would not take place.

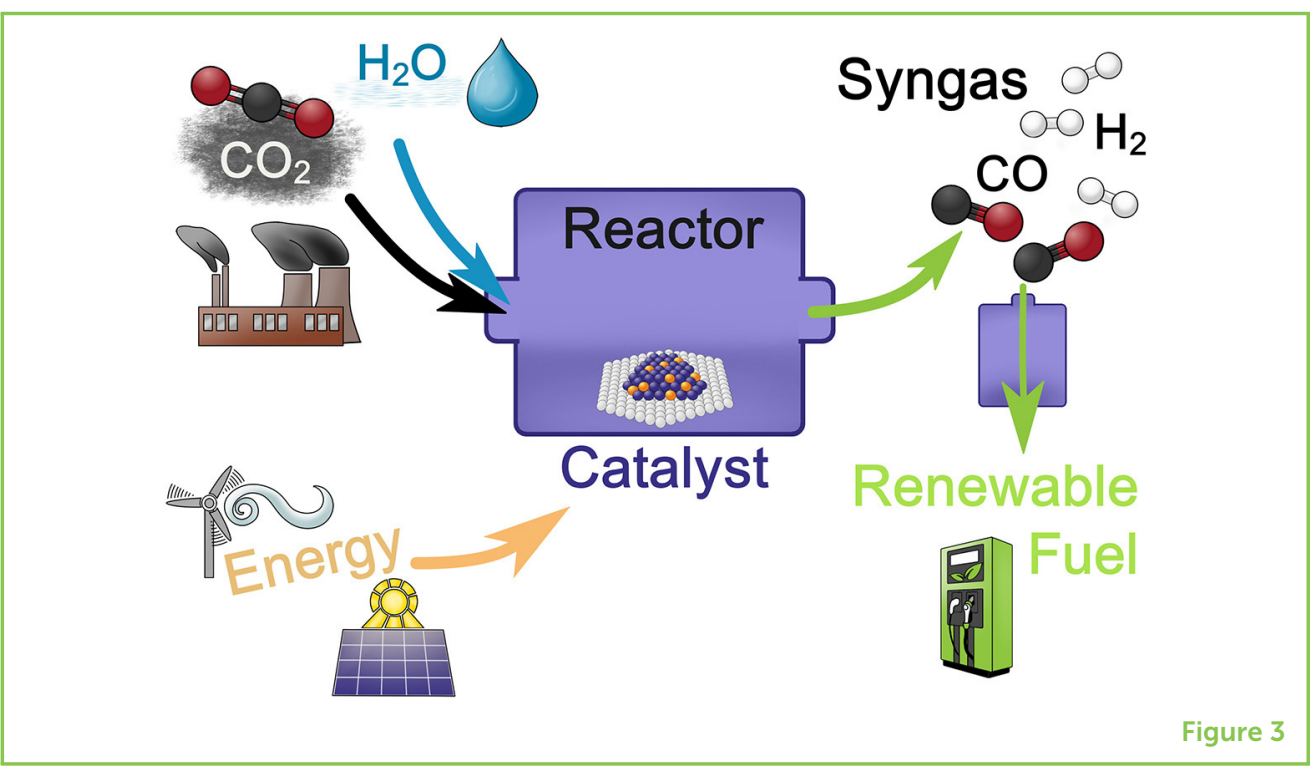

\section{TURNING CARBON DIOXIDE INTO METHANOL}

If you turn a chemical like carbon dioxide into another chemical, this is called a chemical reaction. When chemical reactions are used to convert energy into fuels, we call these processes chemical energy conversion. There are quite a few different chemical reactions to turn $\mathrm{CO}_{2}$ into methanol. There is a direct way, using only carbon dioxide and hydrogen, and there are other ways with steps in between (Figure 3). All these possibilities seem to be quite easy because there are only very simple chemicals (like hydrogen and water) involved.

However, there is a problem: carbon dioxide is a very stable gas, which means it does not easily react with other chemicals. That means that we must use a catalyst to make $\mathrm{CO}_{2}$ react [4]. A catalyst is a substance that makes a chemical reaction possible that would not happen at all or would only happen very slowly without the catalyst. Finding catalysts that help to produce renewable fuels efficiently and inexpensively is an important field of work for many scientists today.

In Figure 3, we show the ingredients necessary to turn carbon dioxide into methanol in two steps. First, carbon dioxide and water are combined with a catalyst. Then, energy needs to be added to start the chemical reaction that produces syngas, which is short for synthesis gas, a mixture of carbon monoxide and hydrogen. This mixture can then be used to produce renewable fuel like methanol in a second reaction.

\section{TAKE-HOME MESSAGE}

Turning greenhouse gases like carbon dioxide into renewable fuels, such as methanol provides us with a possible way of storing energy. 
To do this, we can harness renewable energy (for instance, wind or solar energy) where and when it is available. We can use the renewable energy in a chemical reaction to produce methanol, and then we can transport the methanol to where we need it or store it for later. This process also allows us to temporarily lower the amount of greenhouse gases in the atmosphere. More importantly, this "recycling" of the carbon dioxide that is already in the atmosphere helps to avoid the release of additional $\mathrm{CO}_{2}$ through the burning of fossil fuels. This might help to reduce global warming and human-made climate change, which are both extremely serious problems of our time.

\section{ACKNOWLEDGMENTS}

We want to thank the European Research Council (ERC) for financial support through the European Union's Horizon 2020 research and innovation programme (grant agreement $n^{\circ}$ 755744/ERC-Starting Grant TUCAS).

\section{REFERENCES}

1. Mitchell, J. F. B. 1989. The greenhouse-effect and climate change. Rev. Geophys. 27:115-39. doi: 10.1029/RG027i001p00115

2. Rädecker, N., and Pogoreutz, C. 2019. Why are coral reefs hotspots of life in the ocean? Front. Young Minds 7:143. doi: 10.3389/frym.2019.00143

3. Olah, G. A., Goeppert, A, and Prakash, G. K. S. 2018. Beyond Oil and Gas: The Methanol Economy. 3rd Edn. Weinheim: Wiley-VCH.

4. Rameshan, C., Li, H., Anic, K., Roiaz, M., Pramhaas, V., Rameshan, R., et al. 2018. In situ NAP-XPS spectroscopy during methane dry reforming on $\mathrm{ZrO}_{2} / \mathrm{Pt}(111)$ inverse model catalyst. J. Phys. Condens. Matter 30:264007. doi: 10.1088/ 1361-648X/aac6ff

SUBMITTED: 15 January 2020; ACCEPTED: 24 November 2020; PUBLISHED ONLINE: 15 December 2020.

EDITED BY: Dominik K. Großkinsky, Austrian Institute of Technology (AIT), Austria

CITATION: Ruh T, Pramhaas V, Bartl P and Rameshan C (2020) How Greenhouse Gases Can Be Used to Store Energy. Front. Young Minds 8:527039. doi: 10.3389/ frym.2020.527039

CONFLICT OF INTEREST: The authors declare that the research was conducted in the absence of any commercial or financial relationships that could be construed as a potential conflict of interest.

COPYRIGHT (C) 2020 Ruh, Pramhaas, Bartl and Rameshan. This is an open-access article distributed under the terms of the Creative Commons Attribution License (CC BY). The use, distribution or reproduction in other forums is permitted, provided the original author(s) and the copyright owner(s) are credited and that the original 


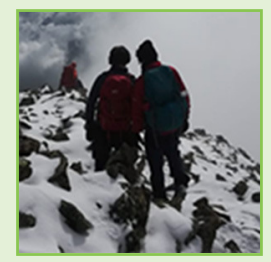

publication in this journal is cited, in accordance with accepted academic practice. No use, distribution or reproduction is permitted which does not comply with these terms.

\section{YOUNG REVIEWERS}

\section{ANDREA, AGE: 15}

I am Andrea, I am 15 and I live in Milano, Italy. I am attending the high school ... well, not in this moment, due to COVID pandemia. At the moment I have on line class, and I do not like it. I practice judo, I enjoy it very much, and I am green belt. Moreover, I love nature, and I like to go to the mountains for trekking, and also for skiing.

\section{ELINOR, AGE: 15}

I enjoy putting my brain to work, discussing my passion for caring for the environment and dance. I like chemistry and biology, physics not so much. I love my cat, a lot ... and stem cells ... and skateboarding.

\section{ERICA, AGE: 13}

Erica is in Year 8. She enjoys drama, sewing and a good thriller. She has a wicked sense of humor, loves to read but does not enjoy Geography or Physics. PE is not at the top of her list either.

\section{GEORGE, AGE: 10}

George is a 10 years old boy that is currently in year 6 . He enjoys reading. His favorites books are the Harry Potter series that he has read 5 times already. George a talented tennis player and has reached the final of several tennis tournaments at his age group. He enjoys school, especially Maths. He also likes drawing, plays the violin and is currently writing a book entitled "King of the Swords." He speaks English and a bit of Greek.

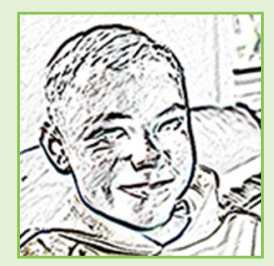

\section{IOLO, AGE: 13}

My hobbies are BMX'ing, playing video games, reading, photography, and football (soccer). I love animals and hope to be a zoologist and ecologist 1 day.

\section{AUTHORS}

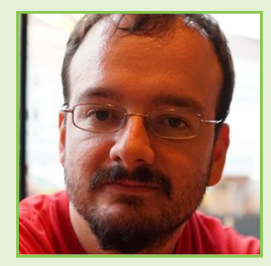

\section{THOMAS RUH}

Thomas Ruh lives in Vienna, where he studied Theoretical Chemistry with a focus on how we can use simulations to predict interesting properties of materials. He got into chemistry because his favorite question as a kid was "Why?" Besides working as a theoretician, he enjoys reading science fiction, fantasy, and mangas, playing chess, and watching movies. He is also a big Pokémon fan. *thomas.ruhatuwien.ac.at 

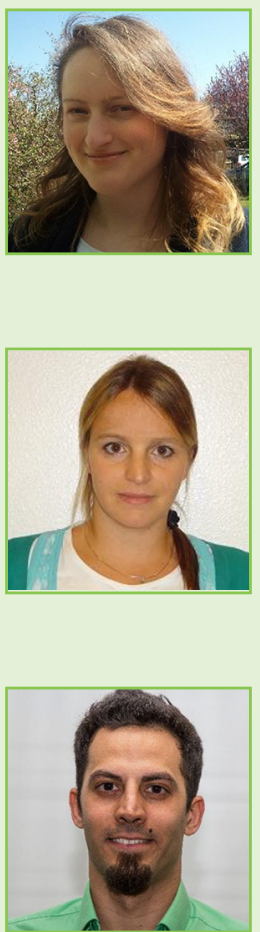

\section{VERENA PRAMHAAS}

Verena Pramhaas is a physicist, now doing research in physical chemistry at the TU Wien. She is mainly focused on using and developing laser-based techniques to study model catalysts and how they compare to catalysts used in industry, which was also the topic of her Ph.D. thesis. Outside of university, she spends most of her time reading, drawing, or crafting.

\section{PATRIZIA BARTL}

Patrizia Bartl was a primary school teacher and is now Professor at the Institute of Elementary and Primary Pedagogics in Innsbruck. There, she instructs students on how to be teachers. She likes to teach young people because they are enquiring and thirsty for knowledge. In her spare time, she likes to be outside in nature with her husband and her three kids.

\section{CHRISTOPH RAMESHAN}

Christoph Rameshan is Assistant Professor at the Institute of Materials Chemistry of TU Wien. His research focuses on understanding chemical reactions using model catalysts, with emphasis on renewable energies. Furthermore, in his ERC project, he tries to find new materials for chemical energy conversion. Besides doing research with his team, he also likes having great times with them outdoors, doing activities like paddle surfing. On the weekends, he likes to be in the mountains with his family, hiking, riding the sledge, or skiing. ${ }^{*}$ christoph.rameshan@utuwien.ac.at 